\title{
PROTEÍNAS DE FASE AGUDA (PFA) EM CÃES
}

Layla Lívia de Queiroz*1, Luma Tatiana Silva Castro ${ }^{2}$, Paula Costa Ariza ${ }^{2}$, Marynis Santos ${ }^{3}$ Maria Clorinda Soares Fioravanti ${ }^{4}$

1. Doutoranda. Escola de Veterinária e Zootecnia da Universidade Federal de Goiás.

Goiânia, Goiás, Brasil. laylalivia@hotmail.com - *autor para correspondência

2. Doutoranda. Escola de Veterinária e Zootecnia da Universidade Federal de Goiás. Goiânia, Goiás, Brasil.

${ }^{3}$ Graduanda. . Escola de Veterinária e Zootecnia da Universidade Federal de Goiás. Goiânia, Goiás, Brasil.

${ }^{4}$ Professora Doutora da Escola de Veterinária e Zootecnia da Universidade Federal de Goiás. Goiânia, Goiás, Brasil.

Recebido em: 08/04/2016 - Aprovado em: 30/05/2016 - Publicado em: 20/06/2016 DOI: 10.18677/Enciclopedia_Biosfera_2016_092

\section{RESUMO}

As proteínas de fase aguda (PFAs) são biomarcadores que podem ser utilizados em diversos processos inflamatórios ou infecciosos como ferramentas de diagnóstico precoce ou indicadores de prognóstico e para acompanhamento da evolução da doença e sucesso do tratamento empregado. A resposta de fase aguda (RFA) é considerada uma resposta inespecífica do organismo diante de alguma injúria celular ou tecidual e, essa resposta se apresenta com aumento ou redução das PFAs. As PFAs podem ser classificadas como positivas (que aumentam a concentração durante a RFA), ou negativas (que reduzem sua concentração durante a RFA), e como maiores ou menores, de acordo com a amplitude de aumento ou redução diante de uma RFA. A técnica padrão para identificação das PFAs é a eletroforese, entretanto, algumas PFAs podem ser identificadas e quantificadas por métodos de ELISA, radioimunoensaio, nefelometria, imunoturbidimetria e análise de RNA. As principais PFAs estudadas em cães são: proteína $C$ reativa, amilóide $A$ sérica, haptoglobina, alfa-1 glicoproteína ácida, ceruloplasmina, fibrinogênio, albumina e transferrina. Os estudos sobre as PFAs em cães ainda são escassos, havendo uma grande área ainda a ser explorada.

PALAVRAS-CHAVE: biomarcadores, caninos, resposta de fase aguda.

\section{ACUTE PHASE PROTEINS IN DOGS}

ABSTRACT

Acute phase proteins (AFP) are biomarkers that can be used in infectious processes as early diagnostic tools or prognostic indicators and for monitoring disease progression and success of the treatment. The acute phase response (APR) is considered a non-specific response of the body before any cell or tissue injury, and this response appears to increase or decrease the PFAs. The AFP can be classified as positive (rising concentration during APR) or negative (reducing their concentration during APR) and as larger or smaller, according to its amplitude increase or decrease before a FRG. The standard technique is to identify the AFP electrophoresis, however, some AFP can be identified and quantified by ELISA 
method, radioimmunoassay, nephelometry, immunoturbidimetry and RNA analysis. The main PFAs studied in dogs are: C-reactive protein, serum amyloid $A$, haptoglobin, alpha 1-acid glycoprotein, ceruloplasmin, fibrinogen, albumin and transferrin. Studies of the PFAs in dogs are still scarce, there is a large area yet to be explored.

KEYWORDS: acute phase response, biomarkers, dog.

\section{INTRODUÇÃO}

A clínica médica de animais de companhia é uma área da medicina veterinária que tem evoluído constantemente com estudos profundos sobre diagnóstico, evolução, tratamento e prognóstico de doenças que acometem esses animais. No Brasil e em várias partes do mundo, os cães são os principais animais de estimação, que antes viviam na parte externa da casa e agora estão totalmente inseridos no ambiente domiciliar e fazem parte das famílias que os acolhem. Diante disso, a preocupação com a saúde desses animais tem crescido de forma exponencial e inúmeros investimentos e pesquisas estão sendo direcionados a melhoria de métodos de diagnóstico e tratamento de doenças que acometem os cães.

O diagnóstico precoce de doenças é um dos maiores desafios da clínica médica atual, pois quanto antes uma enfermidade é diagnosticada, maiores são as chances de cura, remissão dos sintomas e aumento da sobrevida. Vários métodos diagnósticos têm sido propostos para a identificação antecipada do agente agressor e um importante método é a identificação e quantificação de biomarcadores.

Biomarcadores ou marcadores biológicos podem ser definidos como elementos relacionados às alterações celulares, bioquímicas ou moleculares, mensuráveis em componentes biológicos, tais como tecidos, células ou fluidos. Mais recentemente, a definição foi ampliada para incluir características biológicas que podem ser objetivamente medidas e avaliadas como indicador de processos biológicos normais, patogênicos ou de respostas farmacológicas a intervenções terapêuticas. Na prática, os biomarcadores incluem ferramentas e tecnologias que podem auxiliar na compreensão da previsão, causa, diagnóstico, progressão, regressão ou o resultado do tratamento de uma doença. As proteínas de fase aguda são biomarcadores relacionados a presença de reação inflamatória (ECKERSALL \& BELL, 2010).

Após qualquer tipo de agressão ao organismo ocorre ativação do sistema imune inato e adquirido para promover a defesa e manutenção da saúde. Dentre os mecanismos do sistema inato ocorre a resposta de fase aguda (RFA), que é apresentada com elevação ou redução de proteínas séricas, febre, leucocitose e alterações hormonais (ECKERSALL \& BELL, 2010). A RFA pode ser considerada um dos marcadores mais precoces para diagnóstico, acompanhamento e prognóstico de processos patológicos ou doenças (CERÓN et al., 2005).

O advento da eletroforese permitiu a pormenorização das proteínas e sua utilização para monitorar processos inflamatórios, alterações nutricionais e/ou infecciosas. Para esse tipo de avaliação é recomendado que várias PFAs sejam avaliadas em conjunto, de preferência comparando animais enfermos com animais saudáveis (GRUYS et al.,2005).

As principais PFAs relatadas na literatura são: proteína C-reativa, amiloide $A$ sérica, haptoglobina, alfa-1 glicoproteína ácida, ceruloplasmina, fibrinogênio, albumina e transferrina. Para a espécie canina, a PFA mais estudada, relatada e que apresenta maior importância na clínica médica é a proteína C-reativa. Assim, perfis 
de PFAs tem sido propostos para diferenciar estágios de doenças bem como fornecer informações sobre a evolução da doença e resposta ao tratamento empregado (CALDIN et al., 2009).

Na medicina a investigação das PFAs tem sido utilizada há várias décadas como biomarcadores de inflamação, infecção e trauma. No entanto, na medicina veterinária esses estudos são recentes, e têm se mostrado cada vez mais promissores, principalmente no que diz respeito ao prognóstico de enfermidades graves (ECKERSALL \& BELL, 2010).

Com esta revisão de literatura objetivou-se definir proteínas de fase aguda, descrever as classificações das PFAs, os métodos de mensuração e as principais PFAs com aplicação para a clínica médica de cães e as doenças relacionadas.

\section{REVISÃO DE LITERATURA Definição}

Proteínas de fase aguda (PFAs) são marcadores inespecíficos de inflamação precoces e sensíveis, capazes de detectar infecções subclínicas antes que ocorra elevação do número de leucócitos circulantes (CALDIN et al., 2009). Essas proteínas alteram suas concentrações em mais de $25 \%$ em resposta à estimulação de citocinas pró-inflamatórias em processos de doença (ECKERSALL \& BELL, 2010). As alterações nas PFAs, que ocorrem a partir de desafios internos ou externos (MURATA et al., 2004), fazem parte da resposta de fase aguda (CERÓN et al., 2005).

A resposta de fase aguda é uma reação inflamatória inespecífica do sistema imune inato dos animais em resposta a traumas, infecções e inflamações. A RFA ocorre com objetivo de evitar o crescimento microbiano, reestabelecer a homeostase e manter o estado de saúde do indivíduo (GRUYS et al., 2005). Além das alterações nas PFAs, a RFA pode se manifestar nos organismos de diferentes formas como febre, leucocitose, elevação do cortisol sérico, redução das concentrações de tiroxina, ferro e zinco e mudanças metabólicas como lipólise, gliconeogênse e catabolismo muscular (CERÓN et al., 2005).

Estudos das PFAs e RFA têm sido realizados na medicina em larga escala e, na medicina veterinária, esta área de investigação teve seu início em 1990. As aplicações na prática clínica das PFAs incluem diagnóstico, prognóstico, avaliação do estado de saúde e bem-estar dos animais. A presença de RFA em cães com doenças não infecciosas pode indicar inflamação grave concomitante (CALDIN et al., 2009).

A maioria das PFAs é sintetizada no fígado, pelos hepatócitos, por meio de estimulação por citocinas pró-inflamatórias, como as interleucinas 1 e 6 e o fator de necrose tumoral (TNF-a) (CERÓN et al., 2005). Essas citocinas são produzidas principalmente por macrófagos. Outros sítios de produção de PFAs relatados incluem os rins, intestinos, coração, pulmão, baço, tecido adiposo e leucócitos (CERÓN et al., 2005).

Apesar da denominação dessas proteínas remeterem à infecções ou inflamações agudas, em caso de estimulação persistente, infecção ou inflamação crônicas, concentrações de PFAs permanecem alterados em comparação aos animais saudáveis (GRUYS et al., 2005). O padrão de resposta dessas proteínas é diferente conforme a espécie animal, sendo que todos os animais possuem as PFAs, mas com importância variada para diferentes tipos de lesões. Nos cães, a proteína 
C-reativa é a mais estudada, e já é confirmada a relação com condições infecciosas e inflamatórias primárias ou secundárias (ECKERSALL \& BELL, 2010).

Não há indícios que idade e sexo influenciem nas concentrações das PFAs, à exceção de gestantes, por conta do estado inflamatório induzido pela invasão embrionária no endométrio (CALDIN et al., 2009). É observado que em casos de infecções bacterianas as alterações nas PFAs são mais intensas do que em infecções virais (GRUYS et al., 2005).

\section{Classificação}

As PFAs podem ser classificadas em negativas ou positivas. As PFAs negativas, como a albumina e a transferrina, são aquelas que tem as concentrações séricas reduzidas em RFA. As PFAs positivas aumentam as concentrações em casos de inflamação com RFA e podem ser exemplificadas pelas proteínas: proteína C-reativa, amiloide A-sérica, haptoglobina, alfa-1 glicoproteína ácida e ceruloplasmina (CERÓN et al., 2005). As PFAs positivas aumentam consideravelmente as concentrações em poucas horas após a infecção, inflamação ou trauma (GRUYS et al.,2005).

As funções das PFAs não estão completamente elucidadas (TVARIJONAVICIUTE et al., 2011). Algumas das funções estabelecidas das PFAs positivas incluem a opsonização e aprisionamento de microrganismos e seus produtos, ativação do complemento, neutralização de enzimas, eliminação de radicais livres e modulação da resposta imune do hospedeiro (GRUYS et al.,2005).

Outra classificação proposta é conforme sua função biológica. Algumas PFAs atuam na defesa do organismo na presença de um patógeno causando mudanças fisiológicas, como exemplo desse tipo de proteína estão: a proteína C-reativa, amilóide A sérica e fibrinogênio. Outras PFAs que possuem ação antioxidante, que protegem o organismo dos metabólitos de oxigênio liberados por células fagocitárias durante a inflamação, como por exemplo a ceruloplasmina (DOS SANTOS \& ALBERTO, 2014).

\section{Métodos de identificação e quantificação}

Para identificação e quantificação das PFAs, primeiramente deve-se atentar para coleta de sangue, que pode ser realizada em cães por venopunção jugular ou cefálica em tubo sem anticoagulante. A amostra deve ser mantida em temperatura ambiente por pelo menos 20 minutos para formação do coágulo, após isto a amostra deve ser centrifugada por dez minutos para separação do soro. Este soro pode ser congelado para uso posterior, ou ser utilizado imediatamente (GRUYS et al., 2005).

A técnica padrão para identificação de proteínas é a eletroforese, que pode ser realizada com diferentes géis como agarose e poliacrilamida, por exemplo. Outras técnicas podem ser utilizadas para a identificação e quantificação das PFAs: ELISA, radioimunoensaio, nefelometria, imunoturbidimetria, western blot e análise de RNA (GRUYS et al.,2005). A identificação das PFAs com a utilização de eletroforese em gel de poliacrilamida contendo dodecil sulfato de sódio (SDS-PAGE) consiste na utilização de um sistema vertical para eletroforese (BATTISTI et al., 2013).

A técnica consiste em colocar a placa de gel em solução tampão de pH 8,5. A amostra de soro a ser analisada deve ser preparada com $10 \mu \mathrm{L}$ de soro sanguíneo 
diluído em $30 \mu \mathrm{L}$ de tampão fosfato e $20 \mu \mathrm{L}$ de gel, aquecidos em água fervente por 10 minutos. Alíquotas de $5 \mu \mathrm{L}$ devem ser depositadas nos fossos da placa de gel, onde inicia-se o estímulo elétrico e promove-se a corrida. Após o término da separação, o gel deve ser corado com Coomassie blue $0,2 \%$ e depois descorado até que as bandas de proteínas se tornem nítidas (BATTISTI et al., 2013). Para quantificação dos pesos moleculares e quantificação das proteínas pode-se utilizar densitometria computadorizada para o escaneamento da amostra (BATTISTI et al., 2013). Pode-se também determinar as concentrações séricas das PFAs utilizando testes comerciais ELISA7, para proteína C-reativa, amiloide A-sérica e haptoglobina.

A proteína C-reativa pode ser quantificada no soro ou em outros fluidos orgânicos por meio de teste Elisa disponível em reagentes comerciais (BATHENNOETHEN et al., 2008). Para determinar a concentração sérica da proteína Creativa, pode-se também utilizar o método turbidimétrico ultrassensível com látex aprimorado. Esse método consiste na aglutinação de partículas de látex recobertas com anticorpo que aglutinam quando entram em contato com a proteína C-reativa presente na amostra, modificando a absorbância conforme a quantidade da proteína que está presente. A alteração da absorbância deve ser quantificada em analisador de química clínica automatizado ou semi-automatizado (BATTISTI et al., 2013).

Em 2014 foi validado um método de imunoturbidimetria PCR específico canino, sendo considerado um método adequado para quantificação rotineira de proteína C-reativa na espécie canina por se tratar de um método preciso, confiável e automatizado (HILLSTRÖM et al. 2014). Existem poucos estudos comparando a obtenção das PFAs em animais por diferentes técnicas, não podendo ser elucidada qual a técnica mais adequada para todos os casos. Ainda não existe consenso internacional para o melhor método de quantificação das PFAs em cães e outras espécies animais (ECKERSALL \& BELL, 2010). Para análise de proteínas, principalmente utilizando análise imunológica, não é adequada a utilização de reação cruzada com testes disponíveis para avaliação em soro humano (ECKERSALL \& BELL, 2010).

\section{Proteína $\mathrm{C}$ reativa}

A proteína C-reativa foi a primeira PFA identificada por aumentar as concentrações após inflamações e infecções. É assim chamada pela habilidade em se ligar à fração $C$ de polissacarídeos de Pneumococcus, e por essa característica que foi descoberta. Sua principal função parece ser a degradação do conteúdo do núcleo de células danificadas. Esta proteína atua na proteção do organismo pela eliminação de agentes infecciosos por meio da ativação do sistema complemento com resultado de ativação da imunidade humoral e celular (CERÓN et al., 2005). Em eletroforese em gel de agarose SDS-page a proteína C-reativa é encontrada em dupla banda com 22 kDa e 24 kDa (JASENSKY et al., 2014).

Essa PFA, produzida pelos hepatócitos, é considerada a maior e mais importante em cães e seres humanos, podendo aumentar em até 200 vezes das as concentrações basais. A proteína C-reativa possui peso molecular de $100 \mathrm{kD}$ divididos em cinco subunidades de $20 \mathrm{kD}$ cada (CERÓN et al., 2005). Pode ser quantificada no soro ou em outros fluidos orgânicos por meio de teste Elisa disponível em reagentes comerciais (BATHEN-NOETHEN et al., 2008).

Não foi demonstrada diferenças nas concentrações de proteína C-reativa entre cães de idades diferentes (BATHEN-NOETHEN et al., 2008) e obesos 
(TVARIJONAVICIUTE et al., 2011). O aumento da concentração da proteína Creativa já foi relatado em cães com diversas infecções bacterianas e virais, incluindo piometra, parvovirose e outras enterites (ECKERSALL \& BELL, 2010). Em outro estudo comparando cadelas saudáveis, gestantes e com piometra, não houve diferença estatística na proteína C-reativa entre os três grupos (SQUASSONI et al., 2011).

Em casos de infecção por Spirocerca lupi, nódulos esofágicos malignos e benignos, o aumento dessa proteína também foi evidenciado. Sendo que, no caso de neoplasias malignas os valores séricos encontrados foram maiores do que nos outros casos (NIVY et al., 2014). No caso da parvovirose, essa proteína demonstrou ser um bom indicador prognóstico, pois os animais com os valores mais elevados foram aqueles que não sobreviveram à doença. Valores séricos dessa proteína acima de $92,4 \mathrm{mg} / \mathrm{L}$ apresentam sensibilidade de $91 \%$ para predizer mortalidade de cães com parvovirose com menos de seis meses de idade (KOCATURK et al., 2010).

A proteína C-reativa tem concentrações séricas elevadas em casos de sepse (valores médios $114 \mu \mathrm{g} / \mathrm{mL} \pm 67$ ) (BATHEN-NOETHEN et al., 2008) e hiperadrenocorticismo com infecção concomitante (CALDIN et al., 2009). Em caso de hiperadrenocorticismo sem infecção concomitante ou sepse, não há diferença nas concentrações da proteína C-reativa dos cães doentes para os saudáveis (CALDIN et al., 2009).

Concentrações séricas aumentadas são relacionadas à neoplasias mamárias malignas ulceradas, com metástase ou com infecções concomitantes em cadelas, indicando que valores séricos aumentados de proteína C-reativa indicam pior prognóstico para essas pacientes (BATTISTI et al., 2013). Em estudo com cães portadores de leishmaniose, a proteína C-reativa mostrou-se significativamente mais elevada nos cães sintomáticos do que nos assintomáticos e em ambos mais elevada do que em cães saudáveis (MARTINEZ-SUBIELA et al., 2002). Em cães com doenças nasais, a proteína C-reativa mostrou-se igualmente aumentada nos animais com aspergilose, rinite e neoplasia nasal (SHEAHAN et al., 2010).

Em cães com erliquiose, foi demonstrado que o aumento da proteína Creativa é mais intenso naqueles com a forma mais grave da doença, que já apresentem mielossupressão, do que naqueles que possuem a doença sem apresentação de mielossupressão (MYLONAKIS et al., 2011).

Foi relatada correlação entre as concentrações séricas de proteína C-reativa e fosfatase alcalina em cães com meningite-arterite responsiva a corticóides (BATHEN-NOETHEN et al., 2008). Ambos têm sua produção pelos hepatócitos aumentada de forma induzida por mediadores pró-inflamatórios, como por exemplo, a interleucina 1 (BATHEN-NOETHEN et al., 2008).

É demonstrado que as concentrações séricas de proteína C-reativa declinam após tratamento e controle de diversas doenças, como, por exemplo, a meningite e arterite responsiva a corticóide (BATHEN-NOETHEN et al., 2008). Podendo ser utilizada como um parâmetro de monitoramento do sucesso do tratamento dessas afecções.

O principal entrave para a utilização desta PFA na rotina laboratorial e clínica em cães está na dificuldade de obtenção de reagentes específicos para esta espécie animal. Embora os anti-soros humanos para proteína C-reativa possam reagir de forma cruzada para a proteína canina, não existem estudos suficientes que corroboram a eficácia dos kits humanos para serem utilizados para diagnóstico em cães (ECKERSALL \& BELL, 2010). 


\section{Amiloide A sérica}

Amiloide A sérica é uma lipoproteína de alta densidade que influencia o transporte de colesterol HDL (high-density lipoprotein) (GRUYS et al., 2005). É produzida principalmente por hepatócitos, mas já foi relatada a produção por intestinos, rins, medula óssea e adipócitos (CERÓN et al., 2005). Dentre suas atuações incluem inibição de proliferação de linfócitos e de células endoteliais, inibição da agregação plaquetária, adesão de linfócitos $\mathrm{T}$ à matriz proteica extracelular, recrutamento de células inflamatórias para o local da infecção, efeito inibitório sobre a febre e efeito quimiotáxico nos monócitos, leucócitos polimorfonucleares e células T (PETERSEN et al., 2004).

É considerada uma das PFAs mais importantes para a espécie canina, pois as concentrações apresentam elevação e declínio rápidos e intensos (SHEAHAN et al., 2010). Esta lipoproteína está aumentada em casos de leishmaniose (MARTINEZSUBIELA et al., 2002), espirocercose e neoplasia esofágica (NIVY et al., 2014). Em caso de doenças nasais como ritine, aspergilose, neoplasia nasal (SHEAHAN et al., 2010) e obesidade em cães da raça Beagle (TVARIJONAVICIUTE et al., 2011), não foram demonstrados aumentos na amilóide A sérica.

\section{Haptoglobina}

A haptoglobina é uma a-2 globulina, considerada proteína constitutiva e uma PFA moderada e um pouco mais tardia, que atinge o pico por volta de cinco dias após o início da inflamação. A haptoglobina canina é muito semelhante à humana, com mesmo teor de aminoácidos e peso molecular, aproximadamente 81kDA3 (PETERSEN et al., 2004).

É uma proteína que, em caso de defesa contra microrganismos ou hemocaterese, se encarrega pelo transporte de hemoglobina em células do sistema mononuclear fagocitário para que haja recuperação do íon ferro. Possui ainda efeitos bacteriostáticos, estimula angiogênese e atua na imunomodulação (PETERSEN et al., 2004).

Concentrações séricas elevadas de haptoglobina foram observadas em cadelas com neoplasias mamárias malignas ou benigninas (BATTISTI et al., 2013), hiperadrenocorticismo (CALDIN et al., 2009), leishmaniose (MARTINEZ-SUBIELA et al., 2002), rinite (SHEAHAN et al., 2010), aspergilose (SHEAHAN et al., 2010), neoplasia nasal (SHEAHAN et al., 2010), e filhotes com parvovirose (KOCATURK et al., 2010).

Cães com hiperadrenocorticismo com ou sem condição inflamatória concomitante apresentam valores séricos de haptoglobina superiores aos animais saudáveis, embora não estatisticamente diferentes, os cães com inflamação associada ao hiperadrenocorticismo apresentem concentrações séricas dessa proteína superiores aos que não possuem a inflamação associada (CALDIN et al., 2009).

\section{Alfa-1 glicoproteína ácida}

A alfa-1 glicoproteína ácida é considerada uma PFA moderada em cães. É sintetizada e secretada principalmente pelos hepatócitos. As principais funções são imunomodulação e ligação à fármacos. O intervalo de referência para alfa-1 
glicoproteína ácida é de 152 a $576 \mathrm{mg} / \mathrm{L}$ e animais recém-nascidos apresentam valores reduzidos (122 $\pm 54 \mathrm{mg} / \mathrm{L}$ ) (YUKI et al., 2010). A elevação da concentração geralmente se inicia cinco dias após a ativação e o pico é alcançado em torno do sétimo dia (CERÓN et al., 2005).

Valores aumentados dessa proteína são observados em caso de hepatite (SEVELIUS \& ANDERSSON, 1994), parvovirose, cinomose, piometra, filariose, insuficiência renal, urolitíase, anemia imunomediada, trauma, hepatite, pancreatite e hiperadrenocorticismo (YUKI et al., 2010). Em cadelas com piometra os valores são maiores nos casos mais severos (HAGMAN, 2011). Nos casos de filariose e hepatopatia, as concentrações de alfa-1 glicoproteína ácida são maiores nos casos agudos do que nos crônicos, podendo ser utilizada como marcador para essa diferenciação (YUKI et al., 2010). Seus valores não se alteram significativamente em caso de neoplasias nasais, aspergilose e ritine (SHEAHAN et al., 2010).

\section{Ceruloplasmina}

A ceruloplasmina é uma proteína que atua no transporte do cobre, na produção de células vermelhas e na proteção celular de compostos gerados pela fagocitose de microrganismos e debris celulares, sendo um importante antioxidante (GRUYS et al., 2005).

Essa proteína é classificada como uma PFA moderada, aumentando as concentrações em duas a três vezes. Dependendo da situação, o pico pode ser alcançado em 24 horas ou até quatro dias (CERÓN et al., 2005). Valores de normalidade relatados na literatura para cães incluem $4,93 \pm 0,62 \mathrm{mg} / \mathrm{dL}$ (MARTINEZ-SUBIELA et al., 2002).

Concentrações séricas elevadas de ceruloplasmina foram relatadas em cães com leishmaniose sintomática $(19 \pm 10,6 \mathrm{mg} / \mathrm{dL})$ e leishmaniose assintomática $(16,9$ $\pm 13,5 \mathrm{mg} / \mathrm{dL}$ ) (MARTINEZ-SUBIELA et al., 2002). Filhotes caninos com parvovirose apresentam aumento discreto a moderado da concentração sérica dessa proteína (KOCATURK et al., 2010).

\section{Fibrinogênio}

O fibrinogênio é uma importante proteína envolvida na homeostase, atuando na formação de fibrina e reparação tecidual. As concentrações séricas de fibrinogênio mostram-se aumentadas em cães com hiperadrenocorticismo com ou sem condição inflamatória associada (CALDIN et al., 2009).

Embora seja uma PFA fácil e barata de ser mensurada, o fibrinogênio parece ter menor sensibilidade para monitoramento da inflamação devido ao aumento em baixa magnitude e porque outras condições, como a coagulação intravascular disseminada e a hiperfibrinogenólise, podem reduzir as concentrações plasmáticas (CERÓN et al., 2005).

\section{Albumina}

A albumina é a proteína mais abundante do plasma sanguíneo. É considerada a mais importante PFA negativa na maioria das espécies animais, inclusive no cão. A diminuição da concentração sérica de albumina pode ocorrer por 
redução na sua produção pelos hepatócitos, ou por aumento das perdas por eliminação renal ou redução da absorção gastrintestinal (GRUYS et al., 2005).

O aumento da albumina ocorre apenas em casos de desidratação. Por outro lado, a redução ocorre em inúmeras situações de inflamação sistêmica, não podendo, portanto, ser utilizada como forma de diagnóstico, mas sim como fator agravante dessas enfermidades (BATHEN-NOETHEN et al., 2008). É comum observar hipoalbuminemia em casos de anorexia, fome e desnutrição (GRUYS et al., 2005).

Concentrações séricas significativamente reduzidas de albumina podem ser observadas nos cães com meningite ou arterite responsiva a esteroide 16, neoplasias mamárias malignas ulceradas (BATTISTI et al., 2013), espirocercose (NIVY et al., 2014), neoplasias esofágicas (NIVY et al., 2014), erlichiose e parvovirose (KOCATURK et al., 2010).

Cães com hiperadrenocorticismo associado à infecção concomitante apresentam concentrações séricas de albumina reduzidas em comparação aos animais com hiperadrenocorticismo descomplicado e aos animais saudáveis (CALDIN et al., 2009). A idade dos cães não influencia as concentrações séricas de albumina (BATHEN-NOETHEN et al., 2008).

\section{Transferrina}

A transferrina ou siderofilina é uma PFA negativa. É responsável pelo transporte sanguíneo de ferro, controle da absorção intestinal e distribuição no organismo. Dentre as condições que podem causar decréscimo nas concentrações desta proteína incluem: insuficiência hepática, inflamação, insuficiência cardíaca, doença renal, leucemias e alterações no metabolismo do ferro. Cães jovens apresentam valores séricos inferiores aos adultos (PIRES et al., 2011).

\section{CONSIDERAÇÕES FINAIS}

As PFAs fornecem informações valiosas quanto ao diagnóstico, acompanhamento terapêutico e prognóstico de diversas doenças em cães. Embora já existam vários estudos relacionando as PFAs à inúmeras doenças, ainda há espaço para novas descobertas da atuação e aplicação dessas proteínas. Inclusive relacionando as diferentes raças dos animais e as doenças que os acometem.

Alguns desafios a serem vencidos com relação às PFAs incluem a padronização e automatização das técnicas de obtenção e quantificação dessas proteínas para a espécie canina, redução de custos, estabelecimento de valores de referência e esclarecimento da importância e aplicabilidade desses exames para os clínicos veterinários de animais de companhia.

No futuro essas PFAs podem ser utilizadas na identificação de infecções subclínicas e para prever e quantificar o risco morbidade ou mortalidade para diversas doenças.

\section{REFERÊNCIAS}

BATHEN-NOETHEN, A. CARLSON, R., MENZEL, D., MISCHKE, R., TIPOLD, A. Concentrations of Acute-Phase Proteins in Dogs with Steroid Responsive MeningitisArteritis. Journal of veterinary internal medicine, Philadelphia, v. 22, n. 5, p. 11491156, 2008. Disponível em: <http://dx.doi.org/10.1111/j.1939-1676.2008.0164.x>. doi:10.1111/j.1939-1676.2008.0164.x 
BATTISTI, M. K. B. DA SILVA, D. M., REUSING M. S. O. , BELTRAME, O. C., SCHMIDT, E. M. S., FAGLIARI J. J., DITTRICH, R. L., GUÉRIOS, S. D. Proteínas de fase aguda em cadelas com neoplasia mamária. Ciência Rural, Santa Maria, v. 43, n. 5, p. 902-907, 2013. Disponível em: < http://dx.doi.org/10.1590/S010384782013000500025>. doi:10.1590/S0103-84782013000500025

CALDIN, M., TASCA, S., CARLI, E., BIANCHINI, S., FURLANELLO, T., MARTINEZSUBIELA, S., CERON, J. J. Serum acute phase protein concentrations in dogs with hyperadrenocorticism with and without concurrent inflammatory conditions.Veterinary Clinical Pathology, Baton Rouge, v. 38, n. 1, p. 63-68, 2009. Disponível em: <http://dx.doi.org/10.1111/j.1939-165X.2008.00087.x> doi: 10.1111/j.1939-165X.2008.00087.x

CERÓN, J. J.; ECKERSALL, P. D.; MARTÍNEZ-SUBIELA, S. Acute phase proteins in dogs and cats: current knowledge and future perspectives. Veterinary Clinical Pathology, Baton Rouge, v. 34, n. 2, p. 85-99, 2005. Disponível em: <http://dx.doi.org/10.1111/j.1939-165X.2005.tb00019.x>. doi:10.1111/j.1939165X.2005.tb00019.x

DOS SANTOS, I. F. C., ALBERTO, D. S., Proteínas de fase aguda em cães e gatos. Arquivos de Ciências Veterinárias e Zoologia da UNIPAR, Umuarama, PR, v. 17, n. 1, p. 55-62, 2015. Disponível em: < http://revistas.bvsvet.org.br/acvzunipar/article/view/25997> Acesso em: 07 abr. 2016

ECKERSALL, P. D.; BELL, R. Acute phase proteins: Biomarkers of infection and inflammation in veterinary medicine. The veterinary journal, London, v. 185, n. 1, p. 23-27, 2010. Disponível em: <http://dx.doi.org/10.1016/j.tvjl.2010.04.009>. doi:10.1016/j.tvjl.2010.04.009

GRUYS, E., TOUSSAINT, M.J.M., NIEWOLD, T.A., KOOPMANS, S.J. Acute phase reaction and acute phase proteins. J Zhejiang Univ Sci B, Hangzhou, v. 6, n. 11, p. 1045-1056, 2005. Disponível em: <http://dx.doi.org/10.1631/jzus.2005.B1045>. doi:10.1631/jzus.2005.B1045

HAGMAN, R. Serum a-1-acid glycoprotein concentrations in 26 dogs with pyometra. Veterinary Clinical Pathology, Baton Rouge, v. 40, n. 1, p. 52-59, 2011. Disponível em: <http://dx.doi.org/10.1111/j.1939-165X.2011.00294.x>. doi:10.1111/j.1939-165X.2011.00294.x

HILLSTRÖM, A., HAGMAN, R., TVEDTEN H., KJELGAARD-HANSEN, M. Validation of a commercially available automated canine-specific immunoturbidimetric method for measuring canine C-reactive protein. Veterinary Clinical Pathology, Baton Rouge, v. 43, n. 2, p. 235-243, 2014. Disponível em: <http://dx.doi.org/10.1111/vcp.12150>. doi:10.1111/vcp.12150

JASENSKY, A. K., BONDZIO, A., MURUGAIYAN, J., SIEBERT, U., ROESLER, U., KOHN, B., EINSPAINER, R. Characterization of the native C-reactive protein (cCRP) and the corresponding liver mRNA in dogs. Biochemical and biophysical research 
communications, Nova York, v. 452, n. 3, p. 462-467, 2014. Disponível em: <http://dx.doi.org/10.1016/j.bbrc.2014.08.090>. doi:10.1016/j.bbrc.2014.08.090

KOCATURK, M., MARTINEZ, S. ERALP O., TVARIJONAVICIUTE, A., CERÓN, J., YILMAZ, Z. Prognostic value of serum acute-phase proteins in dogs with parvoviral enteritis. Journal of Small Animal Practice, Oxoford, v. 51, n. 9, p. 478-483, 2010. Disponível em: <http://dx.doi.org/10.1111/j.1748-5827.2010.00965.x>. doi:10.1111/j.1748-5827.2010.00965.x

MARTÍNEZ-SUBIELA, S. et al. Serum concentrations of acute phase proteins in dogs with leishmaniasis. Veterinary Record, London, v. 150, n. 8, p. 241-244, 2002.

MYLONAKIS, M. E., CERON, J.J., LEONTIDES, L., SIARKOU, V. I., MARTINEZ, S., TVARIJONAVICIUTE, A., KOUTINAS, A. F., HARRUS, S. Serum acute phase proteins as clinical phase indicators and outcome predictors in naturally occurring canine monocytic ehrlichiosis. Journal of Veterinary Internal Medicine, Philadelphia, v. 25, n. 4, p. 811-817, 2011. Disponível em: <http://dx.doi.org/10.1111/j.1939-1676.2011.0728.x>. doi:10.1111/j.19391676.2011.0728.x

MURATA, H.; SHIMADA, N.; YOSHIOKA, M. Current research on acute phase proteins in veterinary diagnosis: an overview. The Veterinary Journal, London, $v$. 168, n. 1, p. 28-40, 2004.

NIVY, R., CALDIN, M., LAVY, E., SHAABON, K., SEGEV, G., AROCH, I. Serum acute phase protein concentrations in dogs with spirocercosis and their association with esophageal neoplasia-a prospective cohort study. Veterinary parasitology, Amsterdam, v. 203, n. 1, p. 153-159, 2014. Disponível em: <http://dx.doi.org/10.1016/j.vetpar.2014.02.001>. doi:10.1016/j.vetpar.2014.02.001

PETERSEN, H. H.; NIELSEN, J. P.; HEEGAARD, P. M. H. Application of acute phase protein measurements in veterinary clinical chemistry. Veterinary research, Paris, v. 35, n. 2, p. 163-187, 2004. Disponível em: <http://dx.doi.org/10.1051/vetres:2004002>. doi:10.1051/vetres:2004002

PIRES L. S. A., DitTRICH, R. L., SOUZA A. C., BERTOL, M. A. F., PATRICIO, L. F.L. Parâmetros utilizados na avaliação do metabolismo do ferro em cães. Ciência Rural, Santa Maria, v. 41, n. 2, p. 272-277, 2011. Disponível em: <http://dx.doi.org/10.1590/S0103-84782011000200015>. doi: 10.1590/S010384782011000200015

SEVELIUS, E.; ANDERSSON, M. Serum protein electrophoresis as a prognostic marker of chronic liver disease in dogs. The Veterinary record, London, v. 137, $\mathrm{n}$. 26, p. 663-667, 1994.

SHEAHAN, D., BELL, R., MELLANBY, R. J., GOW A. G., FRIEND E., HELLER, J., BENCE, L. M., ECKERSALL, P. D. Acute phase protein concentrations in dogs with nasal disease. The Veterinary Record, London, v. 167, n. 23, p. 895, 2010. Disponível em: <http://dx.doi.org/10.1136/vr.c5928>. doi:10.1136/vr.c5928 
SQUASSONI, G. F. M., MOTHEO, T. F., FELICIANO, M. A. R., VICENTE, W. R. R. Concentração sérica de proteína C-reativa em cadelas hígidas, gestantes ou com piometra. Revista Científica Eletrônica de Medicina Veterinária, Garça, SP, n. 17, 2011. em:

http://faef.revista.inf.br/imagens_arquivos/arquivos_destaque/lyZHQ6sejBwfAZs_201 3-6-26-12-9-27.pdf>. Acesso em: 07 abr. 2016

TVARIJONAVICIUTE, A., MARTINEZ, S., GUTIERREZ, A., CERON, J.J., TECLES, F. I. Serum acute phase proteins concentrations in dogs during experimentally shortterm induced overweight. A preliminary study. Research in veterinary science, Oxford, v. 90, n. 1, p. 31-34, 2011. Disponível em: <http://dx.doi.org/10.1016/j.rvsc.2010.05.008>. doi:10.1016/j.rvsc.2010.05.008

YUKI, M.; ITOH, H.; TAKASE, K. Serum a-1-acid glycoprotein concentration in clinically healthy puppies and adult dogs and in dogs with various diseases. Veterinary Clinical Pathology, Baton Rouge, v. 39, n. 1, p. 65-71, 2010. Disponível em: <http://dx.doi.org/10.1111/j.1939-165X.2009.00181.x>. doi:10.1111/j.1939-165X.2009.00181.x 